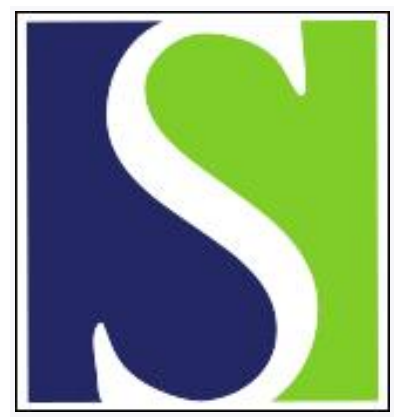

Scand J Work Environ Health 2013;39(3):284-294

https://doi.org/10.5271/sjweh.3341

Published online: 03 Jan 2013, Issue date: 01 May 2013

Long-term effects of an occupational health guideline on employees' body weight-related outcomes, cardiovascular disease risk factors, and quality of life: results from a randomized controlled trial

by Verweij LM, Proper KI, Weel ANH, Hulshof CTJ, van Mechelen W

Overweight and obesity prevention efforts are warranted. We evaluated the effectiveness of a occupational health guideline aimed at preventing weight gain. Guideline-based care was not more effective than usual care after 18 months follow-up on body weight-related outcomes, CVD risk factors, or quality of life. Therefore, we cannot recommend implementation of the guideline in its current form.

Affiliation: Department of Public and Occupational Health, the EMGO Institute for Health and Care Research, VU University Medical Center. Van der Boechorststraat 7, 1081 BT Amsterdam, The Netherlands. ki.proper@vumc.nl

Refers to the following text of the Journal: 2010;36(3):202-215

The following article refers to this text: 2013;39(3):217-220

Key terms: BMI; body mass index; body weight; body weight-related outcome; cardiovascular disease; CVD; obesity; occupational health; occupational health guideline; practice guideline; quality of life; randomized controlled trial

This article in PubMed: www.ncbi.nlm.nih.gov/pubmed/23288297

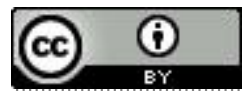




\title{
Long-term effects of an occupational health guideline on employees' body weight-related outcomes, cardiovascular disease risk factors, and quality of life: results from a randomized controlled trial
}

\author{
by Lisanne M Verweij, MSc, ${ }^{1,2}$ Karin I Proper, PhD, ${ }^{1,2}$ Andre NH Weel, MD, PhD, ${ }^{3}$ Carel TJ Hulshof, MD, \\ $P h D, 3,4$ Willem van Mechelen, MD, PhD ${ }^{1,2}$
}

\begin{abstract}
Verweij LM, Proper KI, Weel ANH, Hulshof CTJ, van Mechelen W. Long-term effects of an occupational health guideline on employees' body weight-related outcomes, cardiovascular disease risk factors and quality of life: results from a randomized controlled trial. Scand J Work Environ Health. 2013;39(3):284-294. doi:10.5271/sjweh.3341
\end{abstract}

\begin{abstract}
Objective This study aims to evaluate the effectiveness of a draft occupational health guideline, aimed at preventing weight gain, on employees' body weight-related outcomes, cardiovascular disease (CVD) risk factors, and quality of life.

Methods In a cluster randomized controlled trial including 16 occupational physicians (OP) and 523 employees, guideline-based care was compared to usual care by OP between 2009-2011 in the Netherlands. Guideline-based care consisted of (i) providing advice to employers on how to assess and intervene on the obesogenic work environment, (ii) conducting five face-to-face behavioral change counseling sessions with employees to improve their lifestyles, and (iii) evaluating the outcome and maintaining sections $i$ and ii. Data were collected at baseline and 6,12, and 18-months follow-up. To evaluate the effects of the intervention, multilevel analyses were performed.

Results No significant differences were found between the intervention and control group on waist circumference $[\beta 1.2 \mathrm{~cm}, 95 \%$ confidence interval $(95 \% \mathrm{CI})-0.6-2.9]$, body weight ( $\beta 0.3 \mathrm{~kg}, 95 \% \mathrm{CI}-1.0-1.6)$, body mass index ( $\beta 0.1 \mathrm{~kg} / \mathrm{m} 2,95 \% \mathrm{CI}-0.3-0.5)$, systolic blood pressure ( $\beta 1.7 \mathrm{mmHG}, 95 \% \mathrm{CI}-2.4-5.8)$, diastolic blood pressure ( $\beta 0.3 \mathrm{mmHG}, 95 \% \mathrm{CI}-1.0-0.6)$, cholesterol ( $\beta 0 \mathrm{mmol} / 1,95 \% \mathrm{CI}-0.2-0.2)$, or quality of life indicators after 18-months follow-up. Stratified analyses showed an increase in waist circumference among men $(\beta 2.5 \mathrm{~cm}$, $95 \%$ CI $0.5-4.5)$ and obese intervention participants ( $\beta 2.7 \mathrm{~cm}, 95 \%$ CI $0.6-4.7)$ compared to control participants.
\end{abstract}

Conclusion The draft occupational health guideline was not more effective than usual care. Therefore, the guideline in its current form cannot be recommended for implementation.

Key terms BMI; body mass index; CVD; obesity; practice guideline.

Overweight and obesity are leading preventable causes of death worldwide (1). In 2008, over 2.8 million deaths were due to overweight or obesity $(2,3)$. Both conditions are associated with an increased risk of morbidity, and reduced life expectancy (4) and have been linked with increased healthcare use and medical costs over the past years (5). As prevalence and costs are expected to continue to rise, efforts to prevent overweight and obesity are warranted $(6,7)$.
Lifestyle interventions addressing modifiable risk factors such as physical activity and nutrition have shown to be promising methods for preventing overweight and its related morbidity $(8,9)$. For example, regular physical activity may reduce the risk of cardiovascular disease (CVD), including high blood pressure and diabetes $(10,11)$, as well as prevent weight gain $(12,13)$. A diet low in satured fat may reduce total cholesterol (14), while a diet high in fruits and vegetables

1 Department of Public and Occupational Health, the EMGO Institute for Health and Care Research, VU University Medical Center, Amsterdam, The Netherlands.

2 Body@Work, Research Center Physical Activity, Work and Health, TNO-VUmc, Amsterdam, The Netherlands.

3 Netherlands Society of Occupational Medicine (NVAB), Centre of Excellence, Utrecht, The Netherlands.

4 Coronel Institute of Occupational Health, Academic Medical Center (AMC), Amsterdam, The Netherlands.

Correspondence to: KI Proper, PhD, Department of Public and Occupational Health, the EMGO Institute for Health and Care Research, VU University Medical Center. Van der Boechorststraat 7, 1081 BT Amsterdam, The Netherlands. [E-mail: ki.proper@vumc.nl] 
may reduce the risk of CVD (15) and decrease body weight (16). However, a recent Cochrane review of interventions using counseling and education aimed at behavioral change showed no reduction in total or CVD mortality or clinical events in general populations (17).

Improving physical activity and dietary behavior through lifestyle interventions may not only be beneficial for health, but may also enhance quality of life, decrease healthcare costs, and increase productivity by decreasing illness and absenteeism (3). Occupational physicians (OP) have not conducted many lifestyle interventions although the occupational healthcare setting provides good opportunities to reach employees (18, 19). The Balance@Work project aims to evaluate the effectiveness of an occupational health practice guideline aimed at preventing weight gain among employees in the Netherlands compared to usual care. The intervention effects of guideline-based care on physical activity and dietary behavior after 6-months follow-up are the subject of another article (20). The aim of this study is to evaluate the effectiveness of guideline-based care during 18-months follow-up on body weight-related factors, CVD-risk factors, and quality of life.

\section{Methods}

The cluster randomized controlled trial (RCT) was conducted between 2009-2011 as part of the Balance@Work project. Details of the study design have been published elsewhere (20). The Ethics Committee of the VU University Medical Center approved the study protocol, and all participants signed informed consent. Relevant aspects of the study are reported following the Consort checklist for cluster RCT (21).

\section{Study population}

The Netherlands Society of Occupational Medicine, the professional association of $\mathrm{OP}$, recruited the $\mathrm{OP}$ via a direct mailing to their member registry $(>2100 \mathrm{OP})$. OP were asked to recruit $\geq 1$ companies of medium or large size (>100 workers). Thereafter, OP recruited employees via a health risk appraisal consisting of anthropometric measurements and subsequent health advice. Employees were considered eligible to participate in the RCT when they: (i) had unhealthy levels of daily physical activity or dietary behavior (ie, not complying with public health physical activity or nutrition recommendations) (22-24) and/or were overweight (ie, waist circumference $>80 \mathrm{~cm}$ for women and $>94 \mathrm{~cm}$ for men); (ii) had completed a questionnaire in Dutch at baseline; (iii) were not on sick leave for $>21$ days; and (iv) were not pregnant or had a disease or condition that would make physical activity impossible.

\section{Randomization, blinding, and sample size}

Randomization to the intervention or control group was performed at the OP level. An independent researcher performed the randomization procedure using Random Allocation Software (version 1.0, Isfahan University of Medical Sciences, Iran). The intervention did not allow for blinding of participating OP who were asked not to reveal their group to employees or assistants performing measurements. An a priori power calculation to detect a difference in waist circumference of 1.5 [standard deviation (SD) 4.5 ) $\mathrm{cm}(25)$ with $80 \%$ power and an alpha of 5\%] determined that 175 employees per group were needed at follow-up. Taking a loss to follow-up of $20-40 \%$ into account and possible dependency of employees within OP (regression analyses require independent observations) [intracluster correlation (ICC) of 0.20], a total of 600 employees among 20 OP were required at baseline (20).

\section{Control group}

OP in the control group were asked to provide care as usual, which generally consisted of a health risk appraisal with anthropometric measurements and subsequent health advice.

\section{Intervention group}

OP in the intervention group were additionally asked to provide guideline-based care. The development of the draft occupational health practice guideline has been described in detail elsewhere (20). Briefly, the guideline consists of three sections: (i) prevention at the environmental level (advice for the employer); (ii) prevention at the individual level (advice for the employee); and (iii) evaluation and maintenance.

For the first section, an environment scan was developed that provided an overview of environmental risk factors that could contribute to the prevention of weight gain (eg, availability of bike sheds and shower facilities, pricing strategies in cafeteria). Based on this overview, environmental goals could be prioritized, and feasibility and barriers for implementation could be discussed with the employer and the workers' representative council at baseline and 6-months follow-up.

For the second section, prevention at the individual level, a minimal intervention strategy was developed for OP on how to promote the employee's healthy lifestyle in five 20-30 minute counseling sessions during six months. For this purpose, OP were trained over two days in applying behavioral change counseling, an adapted form of motivational interviewing suitable for brief consultations in healthcare settings (20). After having discussed their risk profile and current health status, employees 
could choose the target behavior they would like to discuss (increasing physical activity, decreasing sedentary behavior, increasing fruit consumption, or reducing the energy intake derived from snacks) in the first counseling session. Next, ambivalence and motivation for change was assessed by discussing pros and cons of behavioral change, and willingness, importance, and perceived confidence to change behavior. OP then guided employees to make a decision on what behavior they needed to change and increased perceived behavioral control by asking employees to formulate a maximum of three implementation intentions. Last, employees set shortand long-term goals. In subsequent sessions, progress and barriers were discussed and short-term goals were adjusted if necessary. No specific weight loss advice was provided as the guideline aimed to prevent weight gain by improving employees' physical activity and healthy dietary behavior. Moreover, obese employees could be referred to the Dutch guideline for treatment of obesity (26). To monitor their behavior, employees were provided with a toolkit containing a waist circumference measure tape, a pedometer, a diary, and leaflets on physical activity and nutrition from the Dutch Heart Foundations and the Netherlands Nutrition Centre.

Finally, the last section of the guideline considered the evaluation and maintenance of the previous sections.

\section{Outcome measures}

Outcome measures of this study were body weightrelated outcomes [ie, waist circumference $(\mathrm{cm})$, body weight $(\mathrm{kg})$, and body mass index (BMI) $\left.\left(\mathrm{kg} / \mathrm{m}^{2}\right)\right]$, biomedical risk factors [ie, systolic and diastolic blood pressure (in $\mathrm{mmHG}$ ), total serum cholesterol ( $\mathrm{mmol} / \mathrm{l})$ ], and quality of life assessed at baseline and 6-, 12-, and 18-months follow-up. OP or their assistants performed the physical measurements. Questionnaires were used to assess quality of life.

\section{Body weight-related outcomes}

Waist circumference was measured as midway between the lower rib margin and the iliac crest to the nearest $0.1 \mathrm{~cm}$. Participants were measured in standing position without heavy outer garments and with emptied pockets, breathing out gently (20). To standardize waist circumference measurement, OP or assistants were provided with a Seca 201 waist circumference measuring tape (Seca, Hamburg, Germany). As blinding of OP was not possible, independent researchers performed control measurements in a random sample of 141 employees during all measurements (8\%). No differences were found between OP- and independent researcher-measured waist circumference [-0.4 (SD 4.5) cm; $\mathrm{P}=0.3]$, among and between intervention and control OP. Additionally, self-reported waist cir- cumference was assessed from 1010 employees during all follow-up measurements ( $80 \%$ ) using a non-stretchable paper measuring tape (range $0-130 \mathrm{~cm}$ ) and written measurement instructions. Compared to OP, employees significantly under-reported their waist circumference by $-1.4(\mathrm{SD} 3.9) \mathrm{cm}(\mathrm{P}<0.01)$. No difference was found between intervention or control participants. As employee measures tended to be less accurate, OP-measured waist circumference remains the best of the two options. Body weight and body height were measured with the participants standing without shoes and heavy outer garments. Participants were asked to push their heels softly to the wall, or the back of the stadiometer. BMI was calculated from measured height and weight as $\mathrm{kg} / \mathrm{m}^{2}$.

\section{CVD risk factors}

Systolic and diastolic blood pressure $(\mathrm{mmHG})$ were measured according to the standard Dutch protocol for blood pressure measurements (27) on employees in a seated position, after several minutes of rest. During the first consultation, both arms were measured twice. In follow-up consultations, the arm with the higher pressure was used if there was a difference of $>10$ $\mathrm{mmHg}$ between measurements. Otherwise, OP were advised to measure the same arm (preferably the left arm) across the remaining measurements in order to standardize measurements (28). As some OP performed blood pressure measurements once but others performed them twice, the first reading was used across all measurements (29). Readings of participants whose arms were measured interchangeably across measurements were excluded from analyses $(\mathrm{N}=13)$. The Reflotron or Accutrend finger capillary assay or lab assessments were used to assess total serum cholesterol $(\mathrm{mmol} / \mathrm{l})$. High density lipoprotein (HDL) and low density lipoprotein (LDL) cholesterol measurements were optional for OP, when feasible. Two intervention $(\mathrm{N}=76)$ and four control $(\mathrm{N}=69)$ OP were able to measure HDL and LDL at baseline. Therefore, these measurements were disregarded in this study.

\section{Quality of life}

We used the validated EQ-5D (30) to measure quality of life. Five questions were asked on self-reported mobility, self-care, activities of daily living, pain, and anxiety. The three answer categories were dichotomized into "no problems" versus "some problems" and "problems", to address the fact that relatively few problems exist in general populations. Health status today was assessed using a visual analogue scale (VAS) ranging from 0 (worst imaginable health state) to 100 (best imaginable health state). Two additional questions were asked: "how would you rate your health in general? ("not good" ver- 
sus "good") and "compared to the last year, my health today is..." ("worse" versus "the same or better").

\section{Statistical analysis}

Baseline differences between the intervention and control group were checked using t-tests for continuous variables and Chi-square tests for categorical variables using PASW software, version 18.0 (IBM, Armonk, NY, USA). To evaluate the intervention effects, multilevel regression analyses were performed for all outcome variables using MlwiN, version 2.18 (Center for Multilevel Modeling, University of Bristol, UK). Multilevel regression analyses are extended linear regression analyses that are most appropriate for analyzing longitudinal data sets containing correlated or clustered observations (31). In our dataset, a three-level data structure exists in which the four measurement occasions are clustered within employees, and employees are clustered within the 16 OP. To correct for this clustering, multilevel analyses adds a single variance parameter of the different regression lines of a level (for example for the 16 different OP) to the regression analyses. For each outcome variable, two multilevel regression analyses were performed. A crude analysis was performed to determine the differences between the intervention and control group at 6-, 12-, and 18-months follow-up reported using the regression coefficient $(\beta)$ and $95 \%$ confidence interval $(95 \% \mathrm{CI})$ for each outcome variable. Analyses were adjusted for the corresponding baseline outcome variable. Next, an adjusted analysis was performed to account for potential confounders (gender, age, irregular work hours).

Confounding was assigned when $>10 \%$ change occurred in the regression coefficient. Effect modification was considered for age, gender, BMI, and the 10-year risk of fatal CVD measured at baseline using $\mathrm{P}<0.10$ of the interaction term to indicate effect modification. The 10-year risk of fatal CVD was estimated using the European Systematic Coronary Risk Evaluation instrument (SCORE), using gender, age, smoking status, total cholesterol and systolic blood pressure (32). To be able to better discriminate between subjects' risk, age was extrapolated to 60 years. This follows the method proposed by Lakerveld et al (33) to address the feature of the SCORE instrument that subjects $<60$ years have almost no 10-year risk of fatal CVD. The continuous SCORE variable was dichotomized at a minimum risk of $10 \%$ for CVD to assess the risk status of our population.

Next, using the output from MlwiN, the dependency of observations [intracluster correlation (ICC)] of employees within OP was assessed for each outcome measure. The ICC was calculated by dividing the between OP variance by the total variance, which is calculated by summation of the between and the within OP variances (31). ICC $>0.10$ indicate a moderate-to-high dependency of observations, in which case multilevel analyses are appropriate as they adjust for this dependency of observations (31). Finally, to test the robustness of our results, we performed sensitivity analyses using imputed data and complete cases data $(31,34) . \mathrm{P}<0.05$ were considered to be significant.

\section{Results}

\section{Participants}

After recruitment, 38 OP expressed an interest to participate. Of these, 28 OP were eligible and randomized to either the intervention or control group. The Balance $a$ Work project started with 7 intervention and 9 control OP because 12 OP withdrew after randomization (figure 1). No significant differences were found between OP who completed the study and OP who withdrew between randomization and baseline on demographic-, behavior-, or job-related characteristics of their worker population. Moreover, intervention OP did not differ significantly from control OP at baseline. During the 6-month intervention period, none of the OP were lostto-follow-up. After 6 months, three OP were lost to follow-up due to ending of their contracts and a reorganization, as a result of which the Balance@Work team took over the follow-up measurements. Moreover, six OP perceived difficulties in collecting data during the follow-up measurements due to pregnancy, sick leave, resistance of an employer, switching jobs, and time constraints; one OP passed away. Therefore, several follow-up measurements were discontinued (figure 1). OP recruited 524 participants between March 2009 and March 2010. All employees met the inclusion criteria. One underweight subject was excluded from analyses because of having a weight gain goal. The baseline characteristics of the two study groups are described in table 1. Intervention employees were significantly different from control employees on age and irregular work hours at baseline. Intervention subjects were younger (46 versus 48 years) and worked less irregular work hours (19\% versus 29\%). After 18 months, 71 intervention (26\%) and 57 control (23\%) employees were lost-to-followup. These subjects were significantly younger, more often female, and had a lower income than those who completed the study, but this did not differ significantly between the intervention or control group.

\section{Intervention effects}

Body weight-related outcomes. Table 2 presents the values for waist circumference, body weight, and BMI for baseline and 6-, 12-, and 18-months follow-up per study 


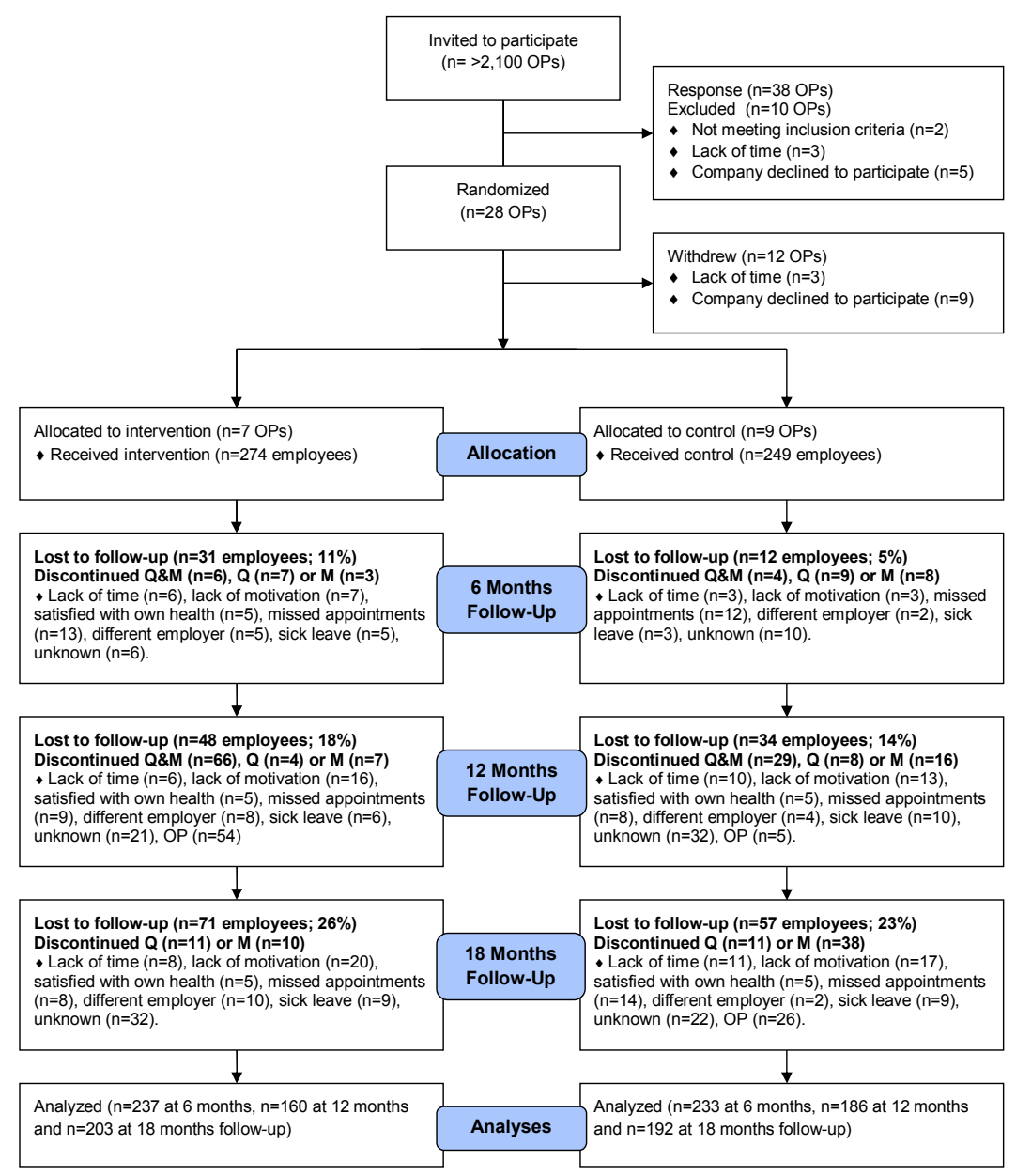

Figure 1. Flow chart of participants during the phases of the Balance@ Work study.

$\mathrm{OP}=$ Occupational physician, $\mathrm{Q}=$ Questionnaire, $\mathrm{M}=$ Anthropometric measurement.

group, as well as the results of the multilevel linear regression analyses. In general, no statistically significant intervention effects were found for waist circumference, body weight, and BMI. The dependency of employees within OP (ICC) was $0.15,0.15$, and 0.13 , respectively. Contrary to what could be expected based on the group means, the multilevel analyses at 12-months follow-up showed a significant increase in waist circumference among the intervention group ( $\beta 2.7 \mathrm{~cm}, 95 \%$ CI 0.8-4.6). This difference disappeared in the longitudinal analyses using all follow-up measurements. Moreover, gender and BMI modified the intervention effect on waist circumference. Waist circumference increased among men and women in the intervention group compared to the control group ( $\beta 2.5 \mathrm{~cm}, 95 \%$ CI $0.5-4.5$; and $\beta 0.4 \mathrm{~cm}, 95 \% \mathrm{CI}$ $-1.4-2.0$, respectively). These differences were significant among men. Also, waist circumference increased among normal weight, overweight and obese participants in the intervention group compared to controls $(\beta 0.1 \mathrm{~cm}, 95 \%$ CI $-1.9-2.1 ; \beta 0.6 \mathrm{~cm}, 95 \% \mathrm{CI}-1.1-2.4$, and $\beta 2.7 \mathrm{~cm}$,
95\% CI $0.6-4.7$, respectively). These differences were significant among obese intervention compared to obese control participants.

CVD risk factors. No significant intervention effects were found for systolic and diastolic blood pressure (table 2). Also, no effects were found on total serum cholesterol. The dependency of employees within OP was 0.12 , 0.12 , and 0.08 , respectively. Although all values slightly decreased in both groups at 6-months follow-up, all values regained at 12- and 18-months follow-up.

Quality of life. The intervention did not result in significant effects on quality of life indicators (table 3). A significant increase among the intervention group was found on health status assessed by VAS scale at 18-months follow-up ( $\beta 3.0,95 \%$ CI $0.5-5.5$ ), but this difference disappeared in the longitudinal analyses using all follow-up measurements. Values for the dependency of employees within OP were not applicable. 
Table 1. Baseline characteristics of the study population by treatment group. [CVD=cardiovascular disease; SD=standard deviation]

\begin{tabular}{|c|c|c|c|c|c|c|c|c|c|}
\hline & \multicolumn{3}{|c|}{ Intervention $\mathrm{N}=274$} & \multicolumn{3}{|c|}{ Control N=249 } & \multicolumn{3}{|c|}{ All $N=523$} \\
\hline & $\%$ & Mean & SD & $\%$ & Mean & SD & $\%$ & Mean & SD \\
\hline Gender (male) & 62 & & & 65 & & & 63 & & \\
\hline Age & & 46 & 8 & & 48 & 9 & & $47^{\text {a }}$ & $8^{a}$ \\
\hline Education (college/university) & 55 & & & 51 & & & 53 & & \\
\hline Nationality (Dutch) & 89 & & & 92 & & & 91 & & \\
\hline Income (mean $€$ per month) & & 2118 & 676 & & 2214 & 781 & & 2162 & 727 \\
\hline Married/cohabitating & 81 & & & 85 & & & 83 & & \\
\hline Smoking (yes) & 15 & & & 15 & & & 15 & & \\
\hline \multicolumn{10}{|l|}{ Body mass index (BMI) } \\
\hline Normal weight $\left(\geq 18.5-<25 \mathrm{~kg} / \mathrm{m}^{2}\right)$ & 33 & & & 27 & & & 30 & & \\
\hline Overweight $\left(\geq 25-<30 \mathrm{~kg} / \mathrm{m}^{2}\right)$ & 40 & & & 45 & & & 42 & & \\
\hline Obese $\left(\geq 30 \mathrm{~kg} / \mathrm{m}^{2}\right)$ & 27 & & & 29 & & & 28 & & \\
\hline Chronic disease (yes) & 40 & & & 38 & & & 39 & & \\
\hline Medication use (yes) & 32 & & & 31 & & & 32 & & \\
\hline 10-year risk of fatal CVD (yes) & 7 & & & 8 & & & 8 & & \\
\hline \multicolumn{10}{|l|}{ Type of worker } \\
\hline Blue-collar & 15 & & & 17 & & & 16 & & \\
\hline White-collar & 70 & & & 73 & & & 72 & & \\
\hline Client contact & 15 & & & 10 & & & 13 & & \\
\hline Irregular work hours & 19 & & & 29 & & & $24^{a}$ & & \\
\hline
\end{tabular}

a Significant difference $\mathrm{P}<0.05$.

\section{Discussion}

The aim of this study was to evaluate the effectiveness of a draft occupational health guideline aimed at preventing weight gain among employees in the Netherlands. No significant effects were found on body weight-related outcomes, CVD risk factors, or quality of life. Stratified analyses showed an increase in waist circumference among men and obese intervention participants.

The results of this study on body weight-related outcomes contrasts two meta-analyses of workplace physical activity and nutrition interventions that found moderate evidence for a net decrease in body weight of -1.3 $\mathrm{kg}$ and $-1.2 \mathrm{~kg}$, and BMI of $-0.5 \mathrm{~kg} / \mathrm{m}^{2}$ and $-0.3 \mathrm{~kg} / \mathrm{m}^{2}$, respectively $(13,35)$. Contrary to our study, the majority of the studies in the meta-analyses aimed to reduce CVD risk or improve physical fitness, via programs that often included exercise schemes and that were generally more intensive than ours. A more intensive intervention might thus be needed produce better effects. However, the programs used in many of the trials far exceed what may be feasible in routine clinical practice $(13,17)$. The significant increase in waist circumference among the intervention group at 12-months follow-up may be the result of non-random missing data that occurred due to time constraints at one intervention company. Although multilevel analyses are stated to be appropriate for analyzing data sets with missing data (31), our results suggest our analyses were influenced by non-random missings at the 12 -months measurement. Ignoring these problems may lead to an over- or underestimation of results and significance. The sensitivity analyses revealed that effects on body weight-and health-related outcomes differed slightly between imputed data, multilevel data, and complete cases (data not shown). Nevertheless, it seems unlikely that our conclusions on the effectiveness of the guideline would change if complete data was present, considering the similar lack of results across analyses. Moreover, multilevel analyses are justified as adjustment for the dependency of observations was necessary $(\mathrm{ICC}>0.10)(31)$.

Remarkably, however, obese and male intervention participants increased in waist circumference. A possible explanation may be that the guideline was not suitable for obese employees. Attendance rates among obese participants were significantly lower compared to normal or overweight participants (data not shown). Moreover, others have shown that more intensive interventions may be necessary for obese workers, including guided dieting and physical activity, psychological interventions, and when necessary medication or surgery (26). Obese employees may therefore best be referred to the Dutch guideline for treatment of obesity (26). The increase in waist circumference among male intervention participants was not influenced by attendance rates, but, based on additional interviews, we found that dissatisfied participants under one intervention OP significantly increased waist circumference and body weight (data not shown). Nevertheless, the value of these results could be argued as, although significant, the increase in waist circumference may not have been clinically relevant $(36,37)$.

The short-term evaluation of the guideline (38) 
Table 2. Intervention effects at 6-, 12-, and 18-months on body weight-related measures and risk factors for cardiovascular diseases. [SD=standard deviation; $95 \% \mathrm{Cl}=95 \%$ confidence interval]

\begin{tabular}{|c|c|c|c|c|c|c|c|c|}
\hline & \multicolumn{8}{|c|}{ Overall change } \\
\hline & \multicolumn{3}{|c|}{ Intervention } & \multicolumn{3}{|c|}{ Control } & \multirow[t]{2}{*}{$\beta$} & \multirow[t]{2}{*}{$95 \% \mathrm{Cl}$} \\
\hline & $\mathrm{N}$ & Mean & SD & $\mathrm{N}$ & Mean & SD & & \\
\hline \multicolumn{9}{|c|}{ Waist circumference (cm) } \\
\hline Baseline ${ }^{a}$ & 274 & 94.5 & 13.1 & 248 & 98.0 & 13.5 & 0.4 & $-1.4-2.2$ \\
\hline 6 months & 233 & 94.0 & 12.6 & 222 & 97.3 & 12.1 & 2.7 & $0.8-4.6^{b}$ \\
\hline 12 months & 151 & 95.1 & 13.0 & 175 & 97.2 & 12.5 & 1.1 & $-0.8-3.0$ \\
\hline 18 months & 193 & 93.3 & 12.7 & 154 & 96.8 & 12.2 & 1.2 & $-0.6-2.9$ \\
\hline \multicolumn{9}{|c|}{ Body weight $(\mathrm{kg})^{\mathrm{c}}$} \\
\hline Baseline & 274 & 86.0 & 16.8 & 248 & 87.5 & 17.0 & -0.1 & $-1.5-1.3$ \\
\hline 6 months & 233 & 84.9 & 16.1 & 223 & 87.1 & 16.1 & 0.3 & $-1.1-1.7$ \\
\hline 12 months & 148 & 83.0 & 15.6 & 174 & 87.1 & 16.4 & 0.9 & $-0.5-2.3$ \\
\hline 18 months & 190 & 84.6 & 16.0 & 153 & 86.7 & 15.8 & 0.3 & $1.0-1.6$ \\
\hline \multicolumn{9}{|c|}{ Body mass index $\left(\mathrm{kg} / \mathrm{m}^{2}\right)^{\mathrm{c}}$} \\
\hline Baseline & 274 & 27.6 & 5.0 & 248 & 28.0 & 4.9 & 0 & $-0.4-0.4$ \\
\hline 6 months & 233 & 27.3 & 4.7 & 223 & 27.8 & 4.5 & 0.1 & $-0.3-0.5$ \\
\hline 12 months & 148 & 27.0 & 4.7 & 174 & 27.6 & 4.6 & 0.3 & $-0.1-0.7$ \\
\hline 18 months & 190 & 27.0 & 4.6 & 152 & 27.4 & 4.4 & 0.1 & $-0.3-0.5$ \\
\hline \multicolumn{9}{|c|}{ Systolic blood pressure (mmHG) d } \\
\hline Baseline & 273 & 133.2 & 17.5 & 248 & 138.0 & 20.3 & 1.3 & $-2.8-5.5$ \\
\hline 6 months & 227 & 132.6 & 19.3 & 217 & 134.1 & 15.5 & 1.4 & $-3.0-5.8$ \\
\hline 12 months & 146 & 127.3 & 15.7 & 168 & 133.2 & 15.7 & 2.0 & $-2.4-6.4$ \\
\hline 18 months & 186 & 134.2 & 18.0 & 134 & 135.5 & 16.4 & 1.7 & $-2.4-5.8$ \\
\hline \multicolumn{9}{|c|}{ Diastolic blood pressure $(\mathrm{mmHG})^{d}$} \\
\hline Baseline ${ }^{a}$ & 273 & 83.6 & 10.4 & 248 & 85.6 & 10.8 & 1.1 & $-0.4-2.6$ \\
\hline 6 months & 227 & 83.4 & 10.1 & 217 & 83.5 & 9.6 & -1.2 & $-3.0-0.5$ \\
\hline 12 months & 146 & 80.6 & 9.2 & 168 & 83.9 & 9.7 & 0 & $-1.8-1.8$ \\
\hline 18 months & 186 & 83.1 & 9.7 & 134 & 85.3 & 9.8 & 0.3 & $-1.0-0.6$ \\
\hline \multicolumn{9}{|c|}{ Cholesterol (mmol/l) } \\
\hline Baseline ${ }^{a}$ & 221 & 5.0 & 0.9 & 239 & 5.3 & 1.0 & -0.1 & $-0.3-0.1$ \\
\hline 6 months & 178 & 4.9 & 0.9 & 221 & 5.1 & 0.9 & 0.1 & $-0.2-0.3$ \\
\hline 12 months & 121 & 5.0 & 0.9 & 163 & 5.2 & 0.9 & 0.1 & $-0.1-0.3$ \\
\hline 18 months & 156 & 5.2 & 0.9 & 144 & 5.3 & 1.0 & 0 & $-0.2-0.2$ \\
\hline
\end{tabular}

a Significant difference $(P<0.05)$ between the intervention and control group at baseline.

b Significant difference between groups at follow-up, corrected for baseline values and the dependency of repeated measurements within workers, and of workers within occupational physicians.

c Model corrected for age and irregular work hours.

d Model corrected for age.

showed that directly after the 6-months intervention period, guideline-based care resulted in a more favorable sedentary behavior at work ( $\beta-28$ minutes per day, $95 \%$ CI $-2-54)$ and increased fruit intake ( $\beta 2.1$ pieces per week; 95\% CI 0.6-3.6), but did not improve employees' physical activity, snack intake, or body weight-related outcomes. After 18-months follow-up, only the effect on increased fruit intake ( $\beta 1.9$ pieces per week; $95 \% \mathrm{CI}$ 0.4-3.4) was sustained (39).

The overall lack of effectiveness of the guideline may be due to several factors. First, the guideline may have been poorly implemented, limiting the ability to detect effects. Although attention to both environmental and individual influences was incorporated in the current draft guideline (40), intervention OP did not perform the environmental component and counseling to the full extent necessary (41). Process data indicated that improvements could be made on both the content and performance of the guideline, such as better practical guidance or materials for OP, better training on relapse prevention and physician-employer communication skills, and more feedback on changing routines (35). Moreover, one control OP applied co-intervention. Also, control employees received four health risk appraisal with feedback for evaluation purposes as well, which in itself may have motivated control participants to change their behavior (the so-called "Hawthorne effect") (42). These findings suggest that the contrast between the intervention and control group may have been too small. The question remains if the guideline could be effective in case of optimal implementation. Secondary analyses among intervention participants at 6-months follow-up suggested greater results can be achieved on waist circumference and body weight among those with higher attendance ( 5 versus $<5$ counseling sessions) and satisfaction scores ( 8 versus $<8$ on a scale $1-10$ ) (41). These differences, however, were not sustained at 18-months follow-up. Moreover, due to a lack of effect on performance indicators, no one part of the guideline could be identified as being more effective. 
Table 3. Intervention effects at 6-, 12-, and 18-months on quality of life indicators. [OR=odds ratio; $\mathrm{SD}=$ standard deviation; $95 \% \mathrm{Cl}=95 \%$ confidence interval]

\begin{tabular}{|c|c|c|c|c|c|c|c|c|c|c|c|}
\hline & \multicolumn{8}{|c|}{ Overall change } & \multirow[t]{3}{*}{$\mathrm{OR}$} & \multirow[t]{3}{*}{$95 \% \mathrm{Cl}$} & \multirow[t]{3}{*}{ B } \\
\hline & \multicolumn{4}{|c|}{ Intervention } & \multicolumn{4}{|c|}{ Control } & & & \\
\hline & $\mathrm{N}$ & $\%$ & Mean & SD & $\mathrm{N}$ & $\%$ & Mean & SD & & & \\
\hline \multicolumn{12}{|l|}{ Mobility a } \\
\hline Baseline & 274 & 11 & & & 247 & 13 & & & 0.6 & $0.3-1.3$ & \\
\hline 6 months & 230 & 9 & & & 223 & 13 & & & 0.9 & $0.4-2.1$ & \\
\hline 12 months & 156 & 11 & & & 181 & 13 & & & 1.7 & $0.7-3.7$ & \\
\hline 18 months & 191 & 13 & & & 181 & 9 & & & 0.9 & $0.6-1.5$ & \\
\hline \multicolumn{12}{|l|}{ Self-care a } \\
\hline Baseline & 274 & 1 & & & 247 & 2 & & & 0.9 & $0.1-16$ & \\
\hline 6 months & 229 & 0 & & & 229 & 0 & & & 3.8 & $0.4-39$ & \\
\hline 12 months & 156 & 2 & & & 181 & 1 & & & 5.3 & $0.6-47$ & \\
\hline 18 months & 191 & 3 & & & 181 & 1 & & & 3.2 & $0.8-14.0$ & \\
\hline \multicolumn{12}{|c|}{ Activities of daily living a } \\
\hline Baseline & 274 & 25 & & & 247 & 22 & & & 1.0 & $0.5-2.2$ & \\
\hline 6 months & 230 & 18 & & & 223 & 17 & & & 0.7 & $0.3-1.4$ & \\
\hline 12 months & 156 & 19 & & & 181 & 24 & & & 0.7 & $0.3-1.6$ & \\
\hline 18 months & 191 & 14 & & & 181 & 7 & & & 0.8 & $0.4-1.3$ & \\
\hline \multicolumn{12}{|l|}{ Pain a b } \\
\hline Baseline & 274 & 43 & & & 247 & 36 & & & 1.4 & $0.8-2.7$ & \\
\hline 6 months & 230 & 38 & & & 223 & 32 & & & 0.8 & $0.4-1.5$ & \\
\hline 12 months & 156 & 33 & & & 181 & 39 & & & 1.0 & $0.5-2.0$ & \\
\hline 18 months & 191 & 34 & & & 181 & 32 & & & 1.1 & $0.7-1.7$ & \\
\hline \multicolumn{12}{|l|}{ Anxiety a } \\
\hline Baseline & 274 & 16 & & & 247 & 14 & & & 1.6 & $0.8-3.0$ & \\
\hline 6 months & 230 & 15 & & & 223 & 11 & & & 0.6 & $0.3-1.3$ & \\
\hline 12 months & 156 & 11 & & & 181 & 16 & & & 0.6 & $0.3-1.2$ & \\
\hline 18 months & 191 & 8 & & & 181 & 13 & & & 0.9 & $0.6-1.4$ & \\
\hline \multicolumn{12}{|c|}{ Health in general $c, d$} \\
\hline Baseline & 274 & 87 & & & 248 & 87 & & & 0.9 & $0.4-1.9$ & \\
\hline 6 months & 230 & 90 & & & 223 & 90 & & & 1.2 & $0.5-2.8$ & \\
\hline 12 months & 156 & 90 & & & 181 & 87 & & & 0.9 & $0.4-2.0$ & \\
\hline 18 months & 191 & 89 & & & 181 & 90 & & & 1.0 & $0.6-1.6$ & \\
\hline \multicolumn{12}{|c|}{ Health today e, d } \\
\hline Baseline & 274 & 16 & & & 248 & 20 & & & 0.9 & $0.4-1.9$ & \\
\hline 6 months & 230 & 16 & & & 223 & 18 & & & 0.9 & $0.4-2.1$ & \\
\hline 12 months & 156 & 15 & & & 181 & 22 & & & 1.1 & $0.5-2.4$ & \\
\hline 18 months & 191 & 16 & & & 181 & 21 & & & 1.0 & $0.5-1.7$ & \\
\hline \multicolumn{12}{|c|}{ Health today (VAS) f, g } \\
\hline Baseline ${ }^{h}$ & 273 & & 72 & 15 & 247 & & 75 & 13 & & $-1.8-2.7$ & 0.4 \\
\hline 6 months & 230 & & 75 & 14 & 224 & & 77 & 12 & & $-3.1-2.2$ & -0.4 \\
\hline 12 months & 155 & & 74 & 15 & 181 & & 77 & 13 & & $0.5-5.5^{i}$ & 3.0 \\
\hline 18 months & 190 & & 77 & 13 & 180 & & 76 & 14 & & $-0.8-2.8$ & 1.0 \\
\hline $\begin{array}{l}\text { a Dichotomo } \\
{ }^{\mathrm{b}} \text { Model corre } \\
\text { c Dichotomo } \\
{ }^{\mathrm{d}} \text { Model corre } \\
\text { e Dichotomo } \\
{ }^{\mathrm{f}} \text { Visual analc } \\
{ }^{9} \text { Model corr } \\
{ }^{\mathrm{n}} \text { Significant } \\
{ }^{\mathrm{S}} \text { Significant } \\
\text { of workers }\end{array}$ & $\begin{array}{l}\text { =prob } \\
\text { ood. } \\
\text { rk hou } \\
\text { year; 0 } \\
\text { nagin } \\
\text { and ir } \\
\text { etwee } \\
\text { oups }\end{array}$ & $\begin{array}{l}\text { se, } 1= \\
\text { ealth } \\
\text { ar wor } \\
\text { interv } \\
\text { bw-up }\end{array}$ & $\begin{array}{l}\text { same or } \\
, 100=b \\
\text { ours } \\
\text { on and } \\
\text { rrected }\end{array}$ & $\begin{array}{l}\text { ter. } \\
\text { imagin }\end{array}$ & health & e. & & & & & \\
\hline
\end{tabular}

Second, the evaluation of the guideline among a general workforce may have provided little room for improvement in the outcome measures. Two systematic reviews recently described that interventions using counseling and education aimed at behavior change may not reduce CVD morbidity or mortality in general populations $(17,43,44)$. Comparable programs among high-risk populations indeed found better results, such as modest reductions in blood pressure, cholesterol, and weight, possibly because high risk participants are more likely to achieve measurable changes in behavior (18, $44,45)$. The high risk approach however, does not solve the origin of the problem (46). It may be worthwhile to evaluate an adapted form of the guideline among high risk groups, such as populations at risk for CVD, hypertension, or diabetes. To achieve a meaningful 
degree of prevention and protection at the workplace, ultimately a combination of primary, secondary, and tertiary interventions may be needed (46). Also, there is ongoing debate what approach may be most suitable for obesity prevention. Although single and multiple factor interventions have shown positive effects, maintenance of effects is usually problematic (47). In our study, we chose to include both individual and environmental strategies as this combination was suggested as a promising strategy to facilitate change in complex health behaviors among relatively healthy people (48). The feature of our healthcare delivery system to divide complex health problems into smaller, more understandable parts, functions well for acute and simple diseases such as acute appendicitis. For chronic and complex diseases such as obesity, however, multiple factors are often responsible for the disease development or presentation (49). Whether a system that accounts for these multiple factors provides better and more effective care remains to be explored (49).

A final point that should be considered is the quality of the measurement instruments. Despite the use of standardized protocols, the fact that our study was performed in daily practice made it impossible to standardize blood pressure and cholesterol measurements. This is important for evaluative research, as variations in blood pressure and cholesterol measurements may lead to different results $(29,50)$. Nevertheless, we do not feel that these variations affected our study greatly considering our lack of results. As for measuring quality of life, the generic EQ-5D - a standardized health-related quality of life questionnaire developed to provide a simple, generic measure of health for clinical and economic appraisal (30) - may not have been appropriate in our population due to ceiling effects (51). However, among populations with a high gross domestic product (GDP) per capita (eg, the Netherlands) high mean VAS ratings are found (51). Moreover, general populations report few problems on quality of life domains (30). Thus, the assessment of quality of life for evaluation purposes may have limited value in intervention studies using general populations, such as ours.

The strengths of this study include the practice-based nature of the guideline and the minimized risk of contamination due to randomization at the OP level. There were some limitations as well. Due to randomization at the OP level, intervention and control employees were significantly different at baseline with respect to age and irregular work hours. We attempted to resolve this selection bias by controlling for these variables in all analyses. Also, as only a small group of all OP in the Netherlands (2\%) participated in our study, therefore the generalizability of our results may be limited towards the total population of Dutch OP. Our study could thus be considered a pragmatic trial (ie, a trial reflects the heterogeneity of patients in actual clinical practice, minimizes exclusion criteria, and allows for variation in context, diagnosis and treatment), as opposed to an efficacy trial (ie, a trial that determines if an intervention produces the expected result under ideal circumstances) or an effectiveness trial (ie, a trial that measures the degree of beneficial effect under "real world" clinical settings) (36). Moreover, smoking behavior was not included in the evaluation of our study while smoking behavior may influence weight and CVD risk factors (52). As smoking behavior was not a goal of our intervention and it did not differ at baseline between groups, we did not expect to find effects. Nevertheless, because we did not assess this information, it is neither possible for us to check for changes in smoking behavior between the intervention and control condition nor to assess the influence of (changes in) smoking behavior on weight and CVD risk factors. Moreover, the occurrence of non-random missing data at the third measurement is probably due to time constraints at one intervention company; indicating attrition is a major problem. We encourage future statistical research to examine the issue of non-random missing data in multilevel analyses. Finally, many OP perceived difficulties collecting data for the follow-up measurements, indicating supporting structures for OP, such as a linkage group, may be necessary for long-term performance of the guideline (41).

\section{Concluding remarks}

The draft occupational health guideline was not effective in preventing weight gain, reducing CVD risk factors, or improving quality of life during 18-months follow-up among the intervention compared to the control group. Thus, we cannot recommend implementation of the guideline in its current form. It may be worth evaluating an adapted, more intensive form of the guideline among high risk groups. Also, more attention could be paid to maximizing attendance and satisfaction rates, as this may favorably affect results. Finally, future research should determine feasible ways to prevent weight gain effectively via occupational health services among general populations in the workplace.

\section{Acknowledgments}

The Netherlands Organization for Health Research and Development (ZonMw) funded this study (project 120510007). We would like to thank all OP and employees who participated in this study. Trial Registration ISRCTN/73545254 and NTR/1190. The authors declare no conflicts of interest. 


\section{References}

1. Mathers C, Stevens G, Mascarenhas M. Global health risks: mortality and burden of disease attributable to selected major risks. Geneva: World Health Organisation; 2009.

2. Alwan AW, Armstrong T, Cowan M. and Riley L. Global status report on noncommunicable diseases 2010. Geneva: World Health Organization; 2011.

3. Mendis S, Puska P, Norvving B. Global Atlas on Cardiovascular Disease Prevention and Control. Geneva: World Health Organization; 2011.

4. Guh DP, Zhang W, Bansback N, Amarsi Z, Birmingham CL, Anis AH: The incidence of co-morbidities related to obesity and overweight: a systematic review and meta-analysis. BMC Public Health. 2009;9:88. http://dx.doi.org/10.1186/1471-2458-9-88.

5. Yach D, Stuckler D, Brownell KD: Epidemiologic and economic consequences of the global epidemics of obesity and diabetes. Nat Med. 2006;12:62-6. http://dx.doi.org/10.1038/ nm0106-62.

6. Low S, Chin MC, Durenberg-Yap M: Review on epidemic of obesity. Ann Acad Med Singapore. 2009;38:57-9.

7. Poirier P, Giles TD, Bray GA, Hong Y, Stern JS, Pi-Sunyer FX, et al. Obesity and cardiovascular disease: pathophysiology, evaluation, and effect of weight loss: an update of the 1997 American Heart Association Scientific Statement on Obesity and Heart Disease from the Obesity Committee of the Council on Nutrition, Physical Activity, and Metabolism. Circulation. 2006;113:898-918. http://dx.doi.org/10.1161/ CIRCULATIONAHA.106.171016.

8. Lee CD, Folsom AR, Blair SN: Physical activity and stroke risk: a meta-analysis. Stroke. 2003;34:2475-81. http://dx.doi. org/10.1161/01.STR.0000091843.02517.9D.

9. Mente A, de KL, Shannon HS, Anand SS: A systematic review of the evidence supporting a causal link between dietary factors and coronary heart disease. Arch Intern Med. 2009;169:65969. http://dx.doi.org/10.1001/archinternmed.2009.38.

10. Yusuf S, Hawken S, Ounpuu S, Dans T, Avezum A, Lanas F et al. Effect of potentially modifiable risk factors associated with myocardial infarction in 52 countries (the INTERHEART study): case-control study. Lancet. 2004;364:937-52. http:// dx.doi.org/10.1016/S0140-6736(04)17018-9.

11. Stamler J, Stamler R, Neaton JD, Wentworth D, Daviglus ML, Garside D et al. Low risk-factor profile and long-term cardiovascular and noncardiovascular mortality and life expectancy: findings for 5 large cohorts of young adult and middle-aged men and women. JAMA. 1999;282:2012-8. http://dx.doi.org/10.1001/jama.282.21.2012.

12. Weinstein AR, Sesso HD: Joint effects of physical activity and body weight on diabetes and cardiovascular disease. Exerc Sport Sci Rev. 2006;34:10-5. http://dx.doi. org/10.1097/00003677-200601000-00004.

13. Verweij LM, Coffeng J, van MW, Proper KI. Meta-analyses of workplace physical activity and dietary behavior interventions on weight outcomes. Obes Rev. 2011; 12:406-29. http:// dx.doi.org/10.1111/j.1467-789X.2010.00765.x.
14. Hooper L, Summerbell CD, Thompson R, Sills D, Roberts FG, Moore $\mathrm{H}$ et al. Reduced or modified dietary fat for preventing cardiovascular disease. Cochrane Database Syst Rev. 2011;CD002137.

15. Health Council Netherlands. Richtlijnen geode voeding 2006/21 [Nutrition guideline]. The Hague: Health Council Netherlands; 2006.

16. Alinia S, Hels $\mathrm{O}$, Tetens I. The potential association between fruit intake and body weight--a review. Obes Rev. 2009;10:639 47. http://dx.doi.org/10.1111/j.1467-789X.2009.00582.x.

17. Ebrahim S, Taylor F, Ward K, Beswick A, Burke M, Davey SG. Multiple risk factor interventions for primary prevention of coronary heart disease. Cochrane Database Syst Rev. 2011;CD001561.

18. Groeneveld IF, Proper KI, van der Beek AJ, van Mechelen W. Sustained body weight reduction by an individual-based lifestyle intervention for workers in the construction industry at risk for cardiovascular disease: results of a randomized controlled trial. Prev Med. 2010;51:240-6. http://dx.doi. org/10.1016/j.ypmed.2010.07.021.

19. Proper KI, Bakker I, van Overbeek K, Bergstra B, Verheijden MW, Hopman-Rock M et al. Naar een gericht BRAVO beleid door bedrijfsartsen [To a BRAVO policy for occupational physicians]. Report Body@Work TNO-VUmc 2005

20. Verweij LM, Proper KI, Weel AN, Hulshof CT, van Mechelen W. Design of the Balance@Work project: systematic development, evaluation and implementation of an occupational health guideline aimed at the prevention of weight gain among employees. BMC Public Health. 2009;9:461. http://dx.doi.org/10.1186/1471-2458-9-461.

21. Campbell MK, Elbourne D, Altman DG. CONSORT statement: extension to cluster randomized trials. BMJ. 2004;328:702-8. http://dx.doi.org/10.1136/bmj.328.7441.702.

22. Haskell WL, Lee IM, Pate RR, Powell KE, Blair SN, Franklin BA et al. Physical activity and public health: updated recommendation for adults from the American College of Sports Medicine and the American Heart Association. Med Sci Sports Exerc. 2007;39:1423-34. http://dx.doi.org/10.1249/ mss.0b013e3180616b27.

23. Kemper H, Ooijendijk W, Stiggelbout M. Consensus over de Nederlandse Norm voor Gezond Bewegen [Consensus on the Dutch physical acticity norm]. Tijdschr Soc Gezondheidsz. 2000;78:180-3.

24. Health Council of the Netherlands. Guidelines for a healthy diet 2006. Publication no. 2006/21. The Hague: Health Council of the Netherlands; 2006.

25. Kwak L, Kremers SP, Werkman A, Visscher TL, van Baak MA, Brug J. The NHF-NRG In Balance-project: the application of Intervention Mapping in the development, implementation and evaluation of weight gain prevention at the worksite. Obes Rev. 2007;8:347-61. http://dx.doi.org/10.1111/j.1467789X.2006.00304.x.

26. Quality Institute for Health Services Netherlands. Diagnostiek en behandeling van obesitas bij volwassenen en kinderen[Guideline Diagnostics and Treatment of Obesity in adults and children]; Utrecht: Kwaliteitsinstituut voor de Gezondheidszorg CBO; 2008. 
27. Quality Institute for Health Services Netherlands. Cardiovasculair risicomanagement [Cardiovasular Risk Management]. Utrecht: Kwaliteitsinstituut voor de Gezondheidszorg CBO; 2006.

28. Clark CE, Campbell JL, Evans PH, Millward A. Prevalence and clinical implications of the inter-arm blood pressure difference: A systematic review. J Hum Hypertens. 2006;20:923-31. http://dx.doi.org/10.1038/sj.jhh.1002093.

29. Kleefstra N, Houweling ST, Meyboom-de JB, Bilo HJ. Weinig nut van bloeddrukmeting aan beide armen; longitudinale studie naar interarmbloeddrukverschillen en de reproduceerbaarheid daarvan bij patiënten met diabetes mellitus type 2 [Measuring the blood pressure in both arms is of little use; longitudinal study into blood pressure differences between both arms and its reproducibility in patients with diabetes mellitus type 2]. Ned Tijdschr Geneeskd .2007;151:1509-14.

30. Hoeymans N, van Lindert H, Westert GP. The health status of the Dutch population as assessed by the EQ-6D. Qual Life Res. 2005;14:655-63. http://dx.doi.org/10.1007/s11136-004-1214-z.

31. Twisk J. Applied Multilevel Analysis. Cambridge: Cambridge University Press; 2006. http://dx.doi.org/10.1017/ CBO9780511610806.

32. Conroy RM, Pyorala K, Fitzgerald AP, Sans S, Menotti A, De BG et al. Estimation of ten-year risk of fatal cardiovascular disease in Europe: the SCORE project. Eur Heart J. 2003;24:987-1003. http://dx.doi.org/10.1016/S0195-668X(03)00114-3.

33. Lakerveld J, Bot SD, Chinapaw MJ, van Tulder MW et al. Primary prevention of diabetes mellitus type 2 and cardiovascular diseases using a cognitive behavior program aimed at lifestyle changes in people at risk: Design of a randomized controlled trial. BMC Endocr Disord. 2008;8:6. http://dx.doi.org/10.1186/1472-6823-8-6.

34. Twisk J, de Vente W. Attrition in longitudinal studies. How to deal with missing data. J Clin Epidemiol. 2002Apr;55(4):329 37. http://dx.doi.org/10.1016/S0895-4356(01)00476-0.

35. Anderson LM, Quinn TA, Glanz K, Ramirez G, Kahwati LC, Johnson DB et al. The effectiveness of worksite nutrition and physical activity interventions for controlling employee overweight and obesity: a systematic review. Am J Prev Med. 2009;37: 34057. http://dx.doi.org/10.1016/j.amepre.2009.07.003.

36. Godwin M, Ruhland L, Casson I, MacDonald S, Delva D, Birtwhistle $\mathrm{R}$ et al. Pragmatic controlled clinical trials in primary care: the struggle between external and internal validity. BMC Med Res Methodol. 2003;3:28. http://dx.doi. org/10.1186/1471-2288-3-28.

37. Verweij LM, Terwee CB, Proper KI, Hulshof CTJ, Van Mechelen W. Measuring waist circumference: Gaps in knowledge. Public Health Nutr. 2012;25:1. http://dx.doi. org/10.1017/S1368980012002741.

38. Verweij LM, Proper KI, Hulshof CTJ, Weel ANH, Van Mechelen W. The application of an occupational health guideline reduces sedentary behavior and increases fruit intake at work: results of a RCT. Occup Environ Med. 2012;69(7):500. http://dx.doi.org/10.1136/oemed-2011-100377.

39. Verweij LM. Occupational health guideline for preventing weight gain among employees, a (cost)effectiveness study (thesis). Amsterdam: Gildeprint; 2012
40. Shain M, Kramer DM: Health promotion in the workplace: framing the concept; reviewing the evidence. Occup Environ Med. 2004;61:643-8. http://dx.doi.org/10.1136/ oem.2004.013193.

41. Verweij LM, Proper KI, Hulshof CT, van Mechelen W: Process evaluation of an occupational health guideline aimed at preventing weight gain among employees. J Occup Environ Med. 2011;53:722-9. http://dx.doi.org/10.1097/ JOM.0b013e318222af9b.

42. Landsberger HA. Hawthorne Revisited. Ithaca, New York: Cornell University; 1958

43. Robroek SJW, Polinder S, Bredt FJ, Burdorf A. Costeffectiveness of a long-term internet-delivered worksite health promotion program on physical activity and nutrition: a cluster randomized controlled trial. Health Educ Res. 2012 Jun;27(3):399-410. http://dx.doi.org/10.1093/her/cys015.

44. Groeneveld IF, Proper KI, van der Beek AJ, Hildebrandt VH, van Mechelen W. Lifestyle-focused interventions at the workplace to reduce the risk of cardiovascular disease-a systematic review. Scand J Work Environ Health. 2010; 36:202-15. http://dx.doi.org/10.5271/sjweh.2891.

45. van Wier MF, Dekkers JC, Hendriksen IJ, Heymans MW, Ariens GA, Pronk NP et al. Effectiveness of phone and e-mail lifestyle counseling for long term weight control among overweight employees. J Occup Environ Med. 2011;53:680-6. http://dx.doi.org/10.1097/JOM.0b013e31821f2bbb.

46. Rose G. Sick individuals and sick populations. Int J Epidemiol. 1985;14:32-8. http://dx.doi.org/10.1093/ije/14.1.32.

47. Goetzel RZ, Ozminkowski RJ. The health and cost benefits of work site health-promotion programs. Annu Rev Public Health. 2008;29:303-23. http://dx.doi.org/10.1146/annurev. publhealth.29.020907.090930.

48. Gortmaker SL, Swinburn BA, Levy D, Carter R, Mabry PL, Finegood DT et al. Changing the future of obesity: science, policy, and action. Lancet. 2011;378:838-47. http://dx.doi. org/10.1016/S0140-6736(11)60815-5.

49. Matheson GO, Klugl M, Dvorak J, Engebretsen L, Meeuwisse WH, Schwellnus M et al. Responsibility of sport and exercise medicine in preventing and managing chronic disease: applying our knowledge and skill is overdue. $\mathrm{Br} \mathrm{J}$ Sports Med. 2011;45:1272-82. http://dx.doi.org/10.1136/ bjsports-2011-090328.

50. Tolonen H, Ferrario M, Kuulasmaa K. Standardization of total cholesterol measurement in population surveys--preanalytic sources of variation and their effect on the prevalence of hypercholesterolaemia. Eur J Cardiovasc Prev Rehabil. 2005:12:257-67.

51. EuroQol Group. Measuring Self-Reported Population Health: An International Perspective based on EQ-5D. Budapest (Hungary): Springmed Publishing Ltd; 2004.

52. Fiore MC. US public health service clinical practice guideline: treating tobacco use and dependence. Respir Care. 2000;45(10):1200-62.

Received for publication: 19 March 2012 